\title{
Numerical Simulation of Jet Pipe Servo Valve
}

\author{
Ying ZHANG, Junshuo CHEN
}

\begin{abstract}
The jet pipe servo valve (jet valve) is the most widely used flow control servo valve on aircrafts and spacecrafts. However, the valve has not been simulated accurately due to its special structure and complex internal flow field. The structure design and performance analysis of the valve mainly rely on repeated experiments, which greatly limits the development efficiency of the valve. To solve the problem, this paper analyzes the magnetic field, flow field and structure field, all of which are involved in the working of the valve, one by one, and numerically simulate the coupling of the three fields. The simulated results were verified through experiments. Our method can greatly enhance the accuracy of jet valve simulation, providing a good reference to the simulation of various complex electrohydraulic devices.
\end{abstract}

Keywords: coupling; flow field; jet pipe servo valve (jet valve); magnetic field; numerical simulation; structure field

\section{INTRODUCTION}

Flow control servo valve, a key component on aircrafts and space crafts, has been widely used in many fields [1]. Jet pipe servo valve (jet valve) and nozzle flapper valve are the most commonly used two-stage flow control servo valves. The jet valve outperforms the nozzle flapper valve in many aspects, including the self-centering function under failure, the excellence in pollution resistance, the high sensitivity and resolution, and the ability to operate at low voltage [2-4]. As a result, the jet valve has been extensively applied in national defence industry.

The research on jet valves started late in China. The relevant studies are not systematic and are rarely published abroad. The research focus is largely directed to failure reduction by improving processing technique and changing materials [5-8]. China also lags far behind developed countries in the manufacturing of jet valves. The domestic production of jet valves is basically the imitation of imported products. No. 704 Research Institute, China Shipbuilding Industry Corporation (CSIC) is the only company in China capable of producing jet valves.

The inadequate research and backward technique are partly attributable to the complex structure of the jet valve, which is often dubbed as complex electromechanical equipment. To make matters worse, the working process of the valve involves multiple fields, ranging from structure field, electromagnetic field to flow field. The workspace of the valve is always subjected to combined effects of various factors [9-11], making it difficult to determine and predict the valve performance.

At present, there is no report in China about effective mathematical model of the jet valve. Hence, jet valve research mainly relies on repeated experiments, which consume a huge amount of manpower and materials [12]. This calls for a precise and effective way to simulate the jet valve [13] that can be extended to improve the performance of complex electrohydraulic devices with similar structures.

The traditional modelling process generally simplifies the device structure and ignores the complex influencing factors. This is obviously not suitable for such a complex device as jet valve, which often works under harsh conditions. It is impossible to model the jet valve only by theoretical derivation and experiment. The high-precision numerical simulation offers a desirable way to make the impossible possible [14, 15]. For example, the finiteelement method and finite-volume method, two typical numerical simulation strategies, can describe every detail of the device, and achieve a precision unmatched by traditional methods.

Some scholars have carried out relevant researches. Li Ruping used CFD (Computational Fluid Dynamics) to analyse the flow field characteristics of jet pipe servo valve in different working media. Xie Zhigang used CFD to simulate the flow field of jet amplifier in jet pipe servo valve in different states [16-18]. However, the current simulation of the jet pipe servo valve is still static; how to describe the dynamic working process of the jet pipe servo valve with numerical method is still a difficulty.

In light of the above, this paper analyses the magnetic field, flow field and structure field, all of which are involved in the working of the valve, one by one, and numerically simulates the coupling of the three fields. The simulated results were verified through experiments. Our method can greatly enhance the accuracy of jet valve simulation, providing a good reference to the simulation of various complex electrohydraulic devices.

\section{SYSTEM STRUCTURE AND WORKING PRINCIPLE}

Fig. 1 illustrates the structure of the jet valve studied in this research.

As shown in Fig. 1, the jet valve mainly consists of a permanent magnetic moving-iron torque motor, a jet amplifier, a spool assembly and a feedback component. The four components work coordinatively through force feedbacks.

Once the jet tube is deflected, the nozzle at the end of the tube will spray high-pressure oil into two bundles through the two holes beneath the nozzle. The oil in the two bundles will respectively enter the left and right chambers of the spool through the corresponding oil passages [19].

The deflection of the jet tube will make the nozzle deviate from the neutral position of the receiver, causing a difference in the flow rate into the two receiving holes. Thus, there will be a pressure difference between the left and right chambers of the spool. Under the pressure difference, the spool will move and open the oil passage connected to the load chamber. 


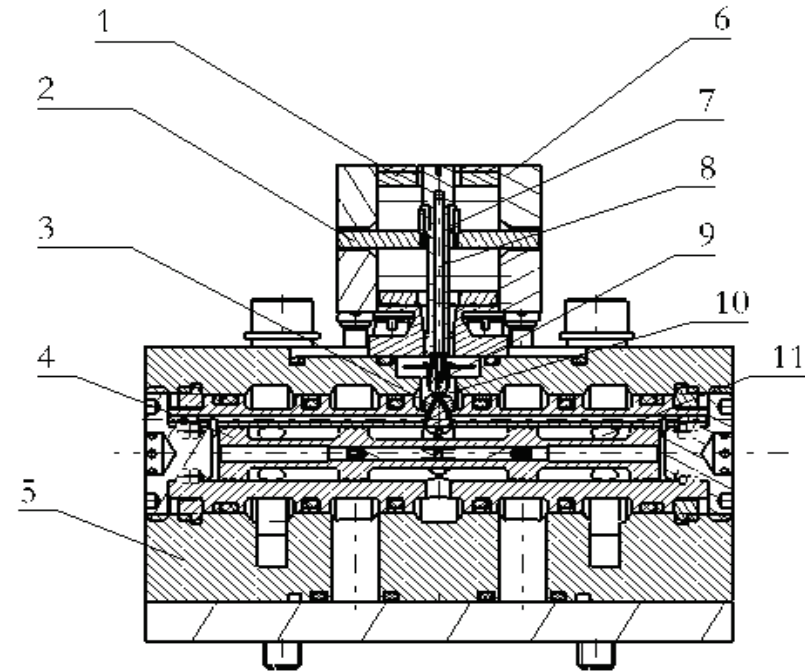

(a) Front view

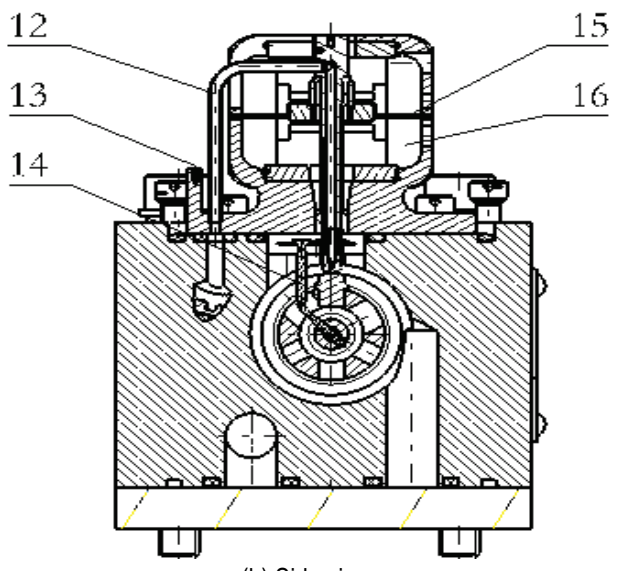

(b) Side view

Figure 1 Structure of the jet valve (1 - Soft magnetic material, 2 - Armature and coil, 3 - Receiving hole, 4 - Spool, 5 - Valve sleeve, 6 - Magnetic- conducting material, 7 - Spring tube, 8 - Jet tube, 9 - Injector, 10 - Overflow cavity, 11 - 0 ring, 12 - Intake line, 13 - Safety wire, 14 - Feedback lever, 15 - Leaf spring, 16 Permanent magnet).

Due to the movement of the spool, the feedback component will deform which hinders the armature deflection and achieves equilibrium. At this time, the opening size of the valve remains constant. In this way, the load flow can be controlled through current adjustment [20, 21].

\section{INDEPENDENT FIELD MODELING AND SIMULATION}

This section analyses the fields involved in the working of the jet valve separately, including the magnetic field distribution after the torque motor is energized, the jet flow field distribution of the jet amplifier, the turbulent flow field distribution between the valve sleeves, and the displacement field distribution of the armature feedback rod assembly when the force is deformed.

\subsection{Modelling and Numerical Analysis of Magnetic Field}

The torque motor has a special spatial structure. Any change to the design or dimension of the structure will greatly affect the distribution of the internal magnetic field. In addition, the boundary conditions of the magnetic field will change in real time with the deflection of the armature.
These influencing factors can be fully considered through numerical analysis with 3D model.

Therefore, Maxwell 3D transient analysis was performed to simulate the internal magnetic field of the torque motor under the rotation of the armature. Considering the electromagnetic eddy current and magnetic flux leakage, the torque motor was meshed into grids with high precision at the air gap. To ensure the meshing accuracy, the grids were corrected against the discontinuity degree of the approximate solution on the interface of the adjacent element. The distribution of magnetic field was solved by transforming the large differential equations between grid nodes into algebraic equations through finite-element method. Furthermore, the relationship between the output torque and the off-angle of the armature was obtained by calculation of the independent field, creating a coupling relationship with the structural dynamics. The $3 \mathrm{D}$ model of the torque motor and the meshed grids of the magnetic field are shown in Fig. 2 below, where different materials are in different colours.
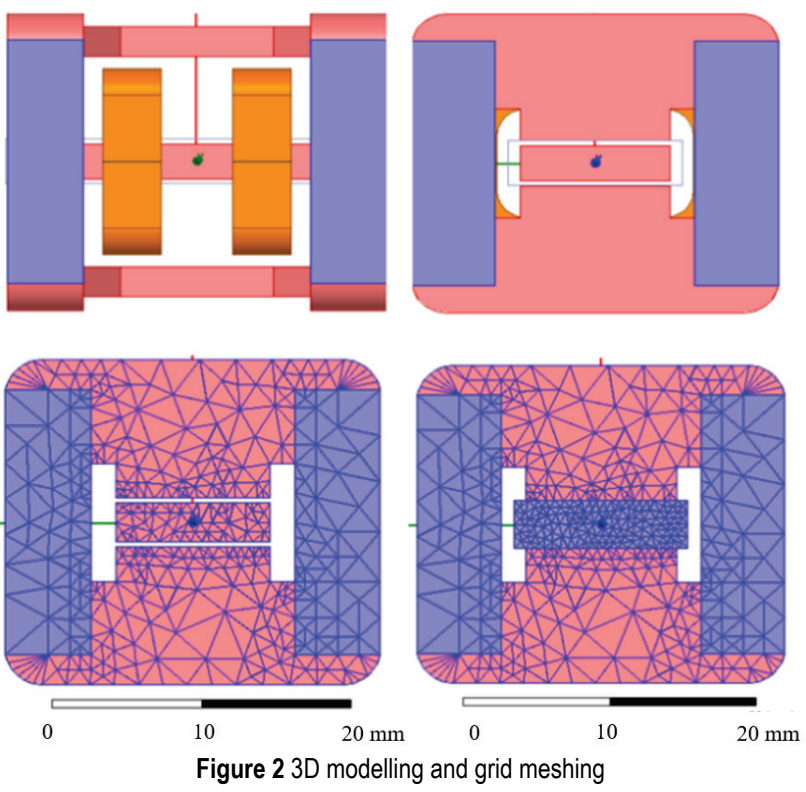

The material of the four permanent magnets (blue) is Alnico52, its remanence can reach 1,3 T, and its coercive force is - $52 \mathrm{kA} / \mathrm{m}$. The upper and lower magnets and armature (pink) are made of soft magnetic alloy $1 \mathrm{~J} 50$ which is easy to magnetize. The number of turns of the copper coils (orange red) wound on the armature is 730 , the relative permeability is 1 , and the conductivity is $58 \times 106$ $\mathrm{Sm}^{-1}$.

By the finite-element method, the transient magnetic field was fully meshed into a myriad of tiny grids. The partial differential equations and boundary conditions of all grid nodes were established. Then, the differential equations were transformed into a linear equation system that can be processed on computer to obtain the magnetic field value of each node in field. The transient computation of 3D magnetic field covers not only transient electromagnetic processes, but also transient mechanical processes, because the transient mechanical deformation directly bears on the transient boundary of the magnetic field. During the computation, the armature angle was limited in the range of $\left(-1,4^{\circ} ; 1,4^{\circ}\right)$, considering the small 
size of the air gap. To process mechanical transients, the displacement or angle should be expressed in discrete form:

$$
\left\{\frac{\mathrm{d} x}{\mathrm{~d} t}\right\}^{t+\Delta t}=\frac{\{x\}^{t+\Delta t}-\{x\}^{t}}{\Delta t}
$$

where, $x$ is the angular displacement of the armature. This nonlinear problem can be solved by the Newton-Raphson iteration method.

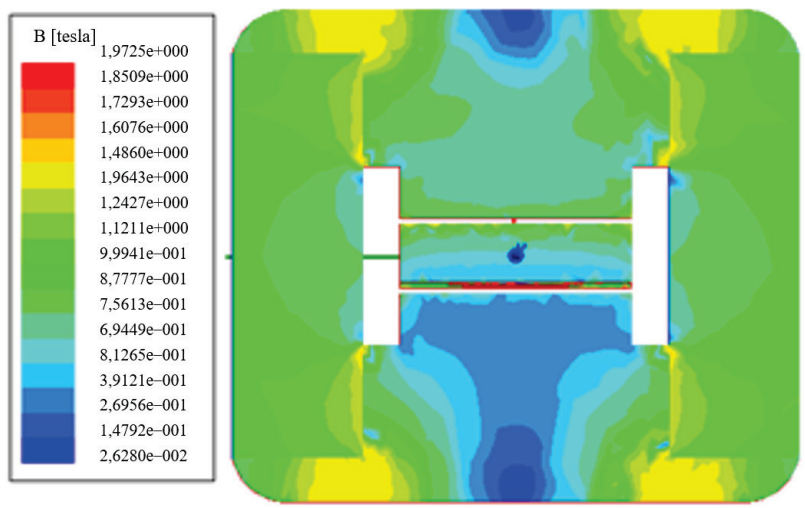

Figure 3 Field distribution of the armature with the deflection of $0,5^{\circ}$

Under the step current of $40 \mathrm{~mA}$, the armature will deflect counter clockwise. Fig. 3 shows the field distribution of the armature with the deflection of $0.5^{\circ}$.

The magnetic field is coupled with the structural deformation as follows: First, the magnetic field generates the electromagnetic moment, which acts on the armature; next, the armature deflects in the air gap, changing the boundary of the magnetic field; finally, the magnetic field is redistributed. Mathematically, the core of the coupling mechanism can be described as the relationship between the output torque of the magnetic field and the deflection of the armature angle.

The step currents of $10 \mathrm{~mA}, 20 \mathrm{~mA}, 30 \mathrm{~mA}$ and $40 \mathrm{~mA}$ are respectively applied to the coil, and the output electromagnetic torque change with the deflection of the armature is shown in Tab. 1.

\begin{tabular}{|c|c|c|c|c|c|}
\hline \\
\hline \multirow{2}{*}{\multicolumn{2}{|c|}{ Torque / $\mathrm{N} \cdot \mathrm{m}$}} & \multicolumn{4}{|c|}{ Input current / A } \\
\hline & & 0,01 & 0,02 & 0,03 & 0,04 \\
\hline \multirow{6}{*}{ 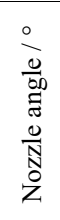 } & 0 & 0,0191 & 0,0383 & 0,0575 & 0,0769 \\
\hline & 0,1 & 0,0411 & 0,0593 & 0,0772 & 0,0958 \\
\hline & 0,2 & 0,0627 & 0,0795 & 0,0988 & 0,1149 \\
\hline & 0,3 & 0,0834 & 0,1042 & 0,1198 & 0,1362 \\
\hline & 0,4 & 0,1040 & 0,1255 & 0,1421 & 0,1595 \\
\hline & 0,5 & 0,1259 & 0,1459 & 0,1632 & 0,1851 \\
\hline
\end{tabular}

So the relationship between the torque, current and deflection angle can be expressed as follows:

$M_{\mathrm{d}}=1,92 i_{\mathrm{c}}+12,03 \theta$

where, $M_{\mathrm{d}}$ is the torque applied to the armature by the magnetic field; $i_{\mathrm{c}}$ is the control current; $\theta$ is the armature angle.

\subsection{Modelling and Numerical Analysis of Flow Field}

There are two parts involved in flow field analysis. One part is the process in which the oil is ejected from the jet nozzle and received by the two receiving holes, another part is the load flow field when the spool moves and the valve opens.

The flow state of the oil is affected by various factors, such as flow velocity, pressure, and structural boundaries. To reflect the complex flow distribution across the fluid region, the flow field should be meshed into countless tiny grids for calculation. Otherwise, it will be impossible to disclose how the oil influences the inner structure of the jet valve. Here, the professional fluid analysis software Fluent is employed to analyze the flow field distribution inside the jet valve.

There are two difficulties in modelling the fluid dynamics equations of the grid nodes: the aviation hydraulic oil has many impurities, and the oil is mixed with particulate matters in different concentrations to adsorb the impurities, which may create bubbles. Under the presence of particles and bubbles, the impacts of the mixed substances on the oil should be considered by using the multi-phase flow model before setting up the fluid equation. Moreover, the flow state model must be adjusted in real time to reflect the constant changes of the oil flow state, which varies in real time with the flow rates. Through the above analysis, the multiphase flow model was introduced to solve the flow field distribution.

(1) Flow field analysis of jet amplifier

The 3D model of the jet amplifier was meshed as Fig. 4. The grids at the jet nozzle and the receiving holes were refined to improve the meshing quality. Considering the computing cost of each grid, the grid division approximated the flow to reduce numerical dissipation.

According to the previous analysis, the multiphase flow model was selected for node calculation to reflect how particle motion affects the flow field. The material properties of each phase were defined as the oil density of $850 \mathrm{~kg} / \mathrm{m}^{3}$ and the dynamic viscosity of $0,01275 \mathrm{~kg} / \mathrm{ms}$. Meanwhile, the boundary conditions were defined as follows: the inlet was simulated as a $21 \mathrm{MPa}$ pressure inlet with a turbulence intensity of $5 \%$, and a hydraulic diameter of 1,2 mm; the outlet was simulated as a 1,3 MPa pressure outlet with a turbulence intensity of $5 \%$, a hydraulic diameter of $6 \mathrm{~mm}$, and an ambient pressure of one bar. For the aviation hydraulic oil, the pollutant grade was NAS7 and the particle mass flow rate was $0,00267 \mathrm{~g} / \mathrm{min}$.

The distribution of oil pressure is greatly affected by bubbles, which are either generated through liquid gasification as the oil pressure drops below the saturated vapour pressure or produced as the air is dissolved in the oil. The bubbles may appear or disappear, depending on the specific conditions, and will not always exist. The motion state of the bubbles cannot be integrated in the multi-phase flow model, and requires separate programming. The preliminary computation shows that, without considering the cavitation effect, the pressure in the flow field minimizes at $0,9 \mathrm{MPa}$, which is much higher than the saturated vapour pressure of the oil. Hence, it is only necessary to program the separation of dissolved air from the oil at low pressure. Three phases were defined for the programming, namely, oil, dissolved air (air_rong) and 
separated air (air_xichu). Among them, the oil is the primary phase, while the other two phases are secondary. The air density and dynamic viscosity were set to 1,225 $\mathrm{kg} / \mathrm{m}^{3}$ and $1,7894 \mathrm{e}-5 \mathrm{~kg} / \mathrm{ms}$. The quality transfer can be written as a user-defined function (UDF) below:

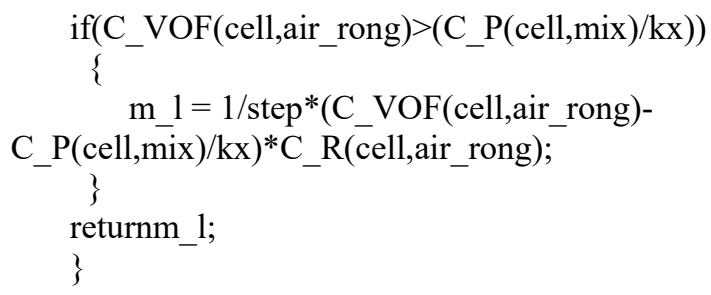

Fig. 4 shows the volume fraction of the gas in the jet flow field when the initial air dissolution volume is $10 \%$ and the nozzle is in the neutral position.

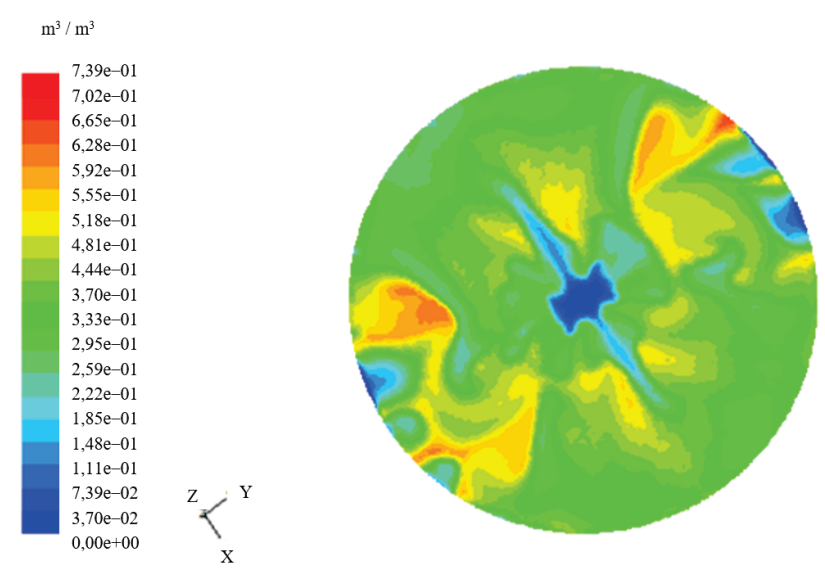

Figure 4 Volume fraction of the gas in the jet flow field

Under the deflection of the jet amplifier, the boundary of the jet flow field will change, which in turn alters the pressure difference between the two bundles on both sides, causing displacement of the spool. The spool displacement will further change the flow field boundary of valve sleeves. The coupling mechanism can be described by the relationship between the following factors: the pressure difference of the two bundles, the spool displacement and the deflection of the nozzle. Among them, the spool displacement can be obtained from the load flow of the jet amplifier. Thus, the flow and pressure features of the jet amplifier should be characterized at various times in the deflection process. The cloud maps of pressure in the flow field are given in Fig. 5, when the armature is at the neutral position.

According to the calculation, with the nozzle deflection the pressure difference between the two receiving holes is shown in Tab. 2.

Table 2 Pressure difference with nozzle angle

\begin{tabular}{|c|c|c|c|c|c|c|}
\hline & \multicolumn{7}{|c|}{ Nozzle angle $/{ }^{\circ}$} \\
\cline { 2 - 7 } & 0 & 0,1 & 0,2 & 0,3 & 0,4 & 0,5 \\
\hline $\begin{array}{c}\text { Pressure } \\
\text { difference } \\
/ \mathrm{Pa}\end{array}$ & 5885 & 6964656 & 11106158 & 13026280 & 13713459 & 15373052 \\
\hline
\end{tabular}

The flow characteristics of jet amplifier at no load can be calculated by connecting two receiving holes. The cloud chart of flow velocity at no load is shown in Fig. 6.

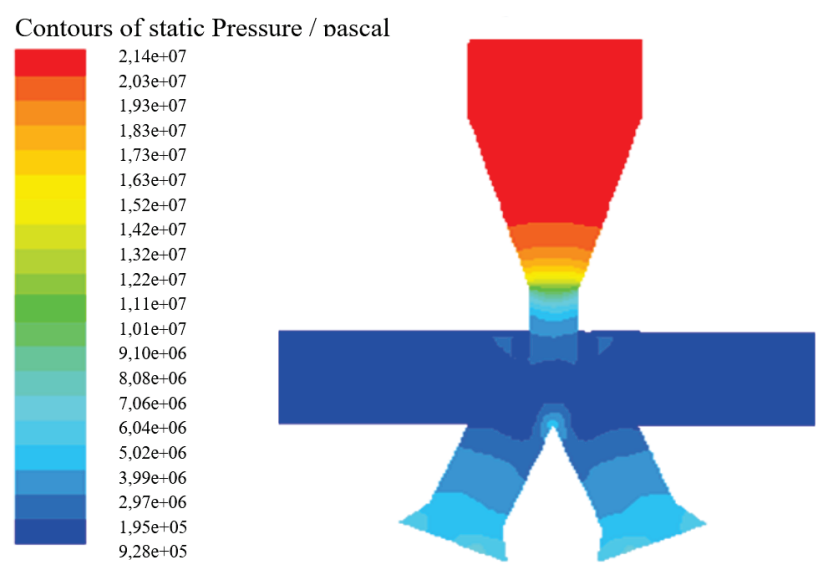

Figure 5 Pressure cloud map of jet amplifier

$\mathrm{m}^{3 / \mathrm{m}^{3}}$
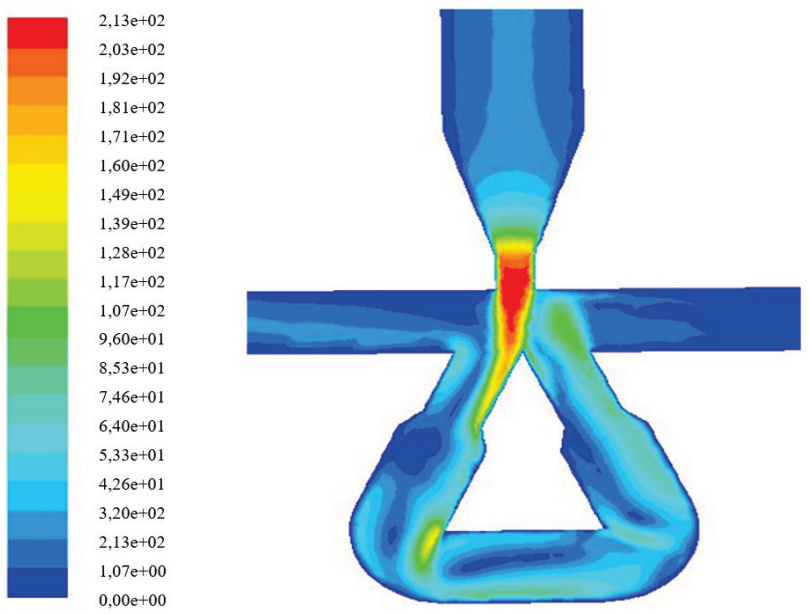

Figure 6 Cloud chart of flow velocity at no load when nozzle angle is 0,1 degrees

Tab. 3 shows the change of flow rate with nozzle deflection angle.

Table 3 Flow rate change with nozzle angle

\begin{tabular}{|c|c|c|c|c|c|c|}
\hline Nozzle angle $/{ }^{\circ}$ & 0 & 0,1 & 0,2 & 0,3 & 0,4 & 0,5 \\
\hline Flow rate $/ \mathrm{L} / \mathrm{min}$ & 0,0002 & 0,142 & 0,266 & 0,327 & 0,381 & 0,398 \\
\hline
\end{tabular}

According to Tab. 2 and Tab. 3, the following function can be derived:

$$
\begin{aligned}
& p_{\mathrm{f}}=1,65 \times 10^{11} x_{j}-2,835 \times 10^{12} Q_{\mathrm{f}}-3,59 \times 10^{9} \theta- \\
& -2,835 \times 10^{12} \times \dot{x}_{\mathrm{v}} \times A_{\mathrm{v}}
\end{aligned}
$$

where, $p_{\mathrm{f}}$ is the pressure difference of the two bundles; $x_{\mathrm{j}}$ is the armature offset; $Q_{\mathrm{f}}$ is the load flow rate; $\theta$ is the offset angle of the armature; $\dot{x}_{v}$ is the spool velocity; $A_{\mathrm{v}}$ is the effective cross-sectional area of the spool.

(2) Numerical analysis on the flow field of spool sleeves

Once the jet valve is unloaded, the spool will move between the sleeves and the load window, and then the high-pressure oil between the sleeves will flow into the load chamber. When the force reaches the equilibrium, the flow output will become constant after the spool stops. The oil rushing will produce steady-state hydraulic power, the main source of system damping on the spool. Therefore, the analysis on the flow field of spool sleeves is equivalent 
to setting up the relationship between opening displacement, load flow and steady-state hydraulic power. Fig. 7 presents the flow distribution when the valve moves slowly to the right at $2 \mu \mathrm{m} / \mathrm{s}$ and gradually opens to $1 \mathrm{~mm}$, and a flow passes between the two load ports.

The flow curve was plotted through data processing for the valve opening of less than $2 \mu \mathrm{m}$.

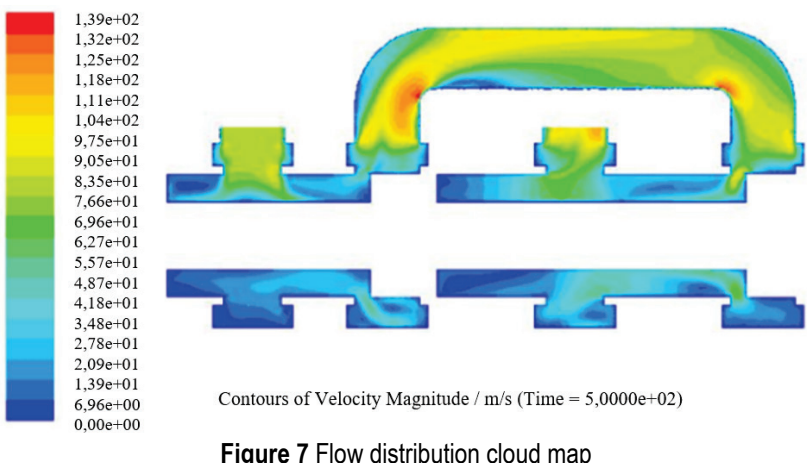

Fig. 8 shows a significant nonlinear relationship between spool displacement and load flow at the initial phase of spool opening, which contradicts the linear relationship in the empirical formula. Since the steadystate hydraulic power of the oil at the opening acts on the valve shoulder, the exact value of the power can be obtained from the mean force on the shoulder. Thus, the relationship between load flow and spool displacement was set up, offering an accurate source of damping for the dynamics analysis of the spool.

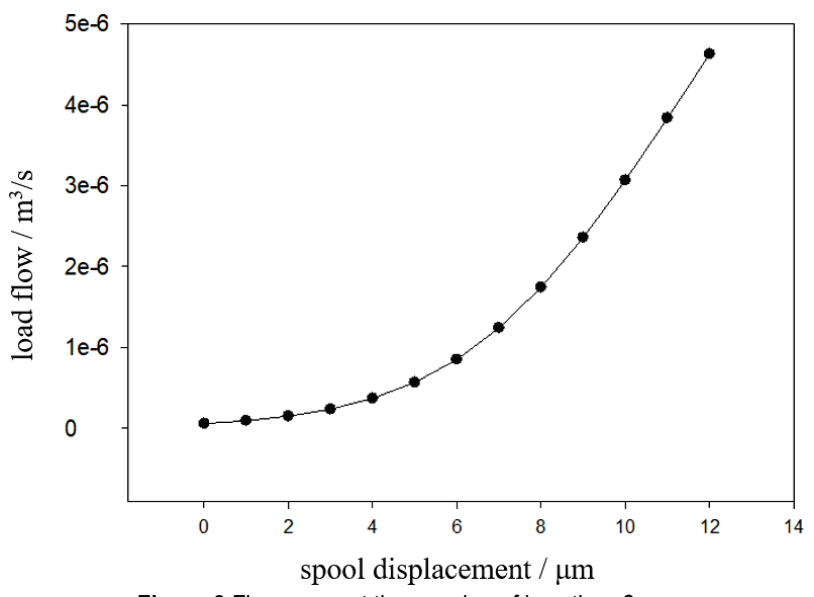

Figure 8 Flow curve at the opening of less than $2 \mu \mathrm{m}$

\subsection{Calculation of Structure Field}

The working principle of the jet valve is to balance the structural forces, and achieve the one-to-one correspondence between the control current and the opening of the load chamber. During the operation, the valve structure withstands both fluid force and the electromagnetic force, which respectively acts on the armature and the valve. Since the deformation stabilization depends on the feedbacks from relevant components, the stabilization effect directly relies on the accuracy of the feedback information.

The components involved in the feedback include: zero adjustment wire, tubing, reed, feedback rod assembly, etc. The complex structure and unique spatial positions of these components need to be analysed with the 3D model. In this paper, the $3 \mathrm{D}$ numerical calculation is applied to determine the stiffness matrix of the grid structure, and differential equations are written by the virtual work principle for finite-element calculation. During the calculation, it is assumed that the armature surface was applied with a $0,15 \mathrm{~N}$ electromagnetic force, while the two ends of the valve were each applied with a $0,5 \mathrm{~N}$ fluid force Fig. 9. Besides, the lower ends of the leaf springs, the zero adjustment wire, the tubing and the spring tube are fixed.

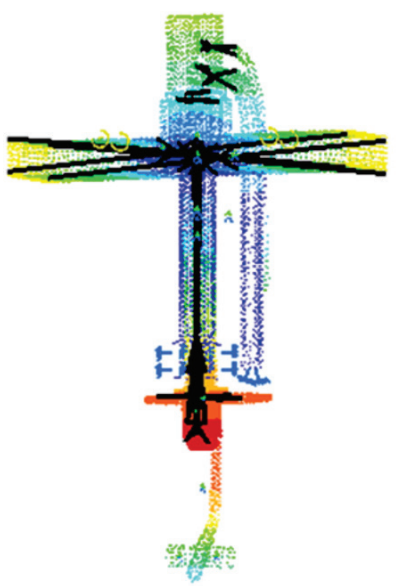

Translational displacement vector. 1

$$
\begin{array}{ll}
\mathrm{mm} & \\
0,217 \\
0,195 \\
0,174 \\
0,152 \\
0,13 \\
0,108 \\
0,0868 \\
0,0651 \\
0,0434 \\
0,0217 \\
0,0217 \\
0
\end{array}
$$

Figure 9 Displacement at the electromagnetic force of $0,15 \mathrm{~N} \cdot \mathrm{m}$ and the fluid force of $0,5 \mathrm{~N}$.

The material is given as follows: the material of the nozzle, spring tube, feedback rod and disc is beryllium bronze, its Young's modulus is $1,3 \times 10^{5} \mathrm{MPa}$, Poisson's ratio is 0,35 , density is $8230 \mathrm{~kg} / \mathrm{m}^{3}$, yield strength is $1,128 \times 10^{3} \mathrm{MPa}$; The material of the armature is $1 \mathrm{~J} 50$, its Young's modulus is $1,57 \times 10^{5} \mathrm{MPa}$, the density is 8200 $\mathrm{kg} / \mathrm{m}^{3}$; The supporting reed material is $3 \mathrm{~J} 1$, the density is $8000 \mathrm{~kg} / \mathrm{m}^{3}$, the Young's modulus is $1,9 \times 10^{5} \mathrm{MPa}$, and the yield strength is $1,9 \times 10^{3} \mathrm{MPa}$; The jet tube material is $1 \mathrm{Cr} 18 \mathrm{Ni} 9 \mathrm{Ti}$, the density is $7900 \mathrm{~kg} / \mathrm{m}^{3}$, the Young's modulus is $1,8 \times 10^{5} \mathrm{MPa}$, and the yield strength is $5,4 \times 10^{2}$ $\mathrm{MPa}$.

By this analysis method, the deformation law of the moving member of the valve was obtained indirectly under the coupling of the electromagnetic force and the fluid force. Meanwhile, the unidirectional coupling between the magnetic field of the armature and the flow field of the valve was described accurately. Since the displacement will be counteracted to the other physical quantities, the armature displacement and spool displacement were taken as the core calculation parameters. The relationships between the displacements and external forces can be expressed as:

$\left\{\begin{array}{c}x_{\mathrm{v}}=-1,1 \times 10^{-3} M_{\mathrm{f}}+3,981 \times 10^{-4} F \\ x_{j}=9,7228 \times 10^{-4} M_{\mathrm{f}}-2,398 \times 10^{-5} F\end{array}\right.$

where, $M_{\mathrm{f}}$ is the electromagnetic force; $F$ is the fluid force on the spool. 


\subsection{Numerical Calculation Based on ANSYS Parametric Design Language (APDL) Programming}

The working of the jet valve is essentially the coupling between the magnetic field, the flow field and the structure field. Specifically, the torque motor generates magnetic field force to drive the armature deflection, the armature deflection changes the jet flow field boundary of the jet amplifier, and then the pressure difference between the two chambers of the spool causes the spool to move. The spool movement will, on the one hand, block the armature through the feedback rod, and, on the other hand, open the passage between the oil source and the load chamber. As a result, the oil will flow into the load chamber, which produces the hydraulic power to curb the spool displacement.

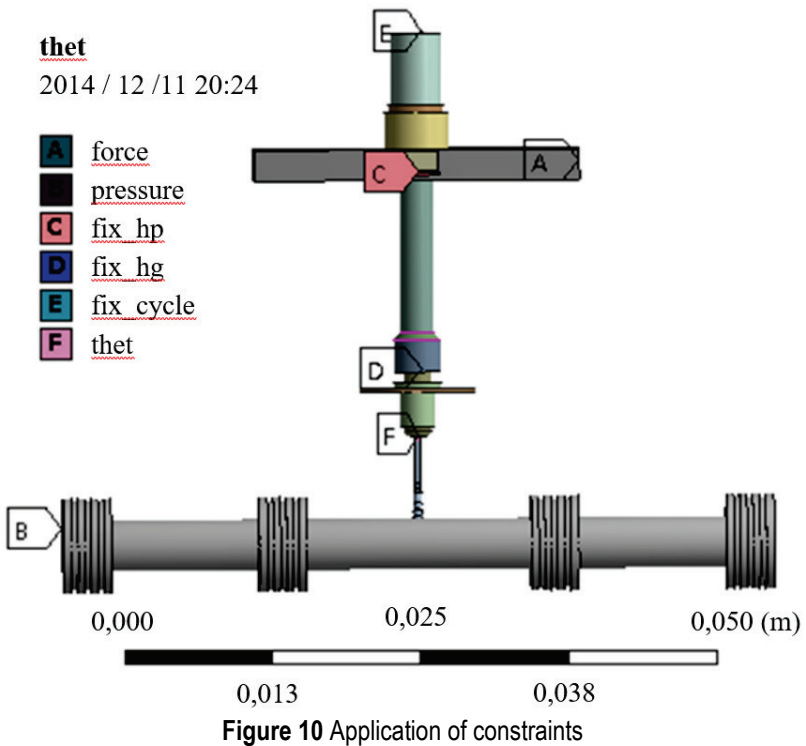

The constraints applied in the numerical calculation are displayed in Fig. 10. Specifically, A represents the force on the armature; $\mathrm{B}$ defines the surface to apply the pressure difference and obtain the spool velocity; C, D and E respectively fix the reeds across the armature, the zero wire, the tubing, and the lower end of the spring tube; $\mathrm{F}$ defines the surface to acquire the deflection angle of the nozzle.

The visual simulation was carried out according to the program in the APDL file, which contains the grid meshing, material properties, constraints, boundary conditions and solution methods. In light of the previous analysis, the armature is under the output torque of the torque motor, which is related to the deflection angle of the armature and the input current Eq. (2). According to Eq. (4), the pressure difference across valve is already known. Moreover, the jet nozzle deflection angle is related to the spool velocity. For the armature-feedback rod assembly, the transient dynamics method was selected due to the constant changes to the load on the armature and the spool. Fig. 10 presents the spool and nozzle displacements simulated at the input current of $15 \mathrm{~mA}$.
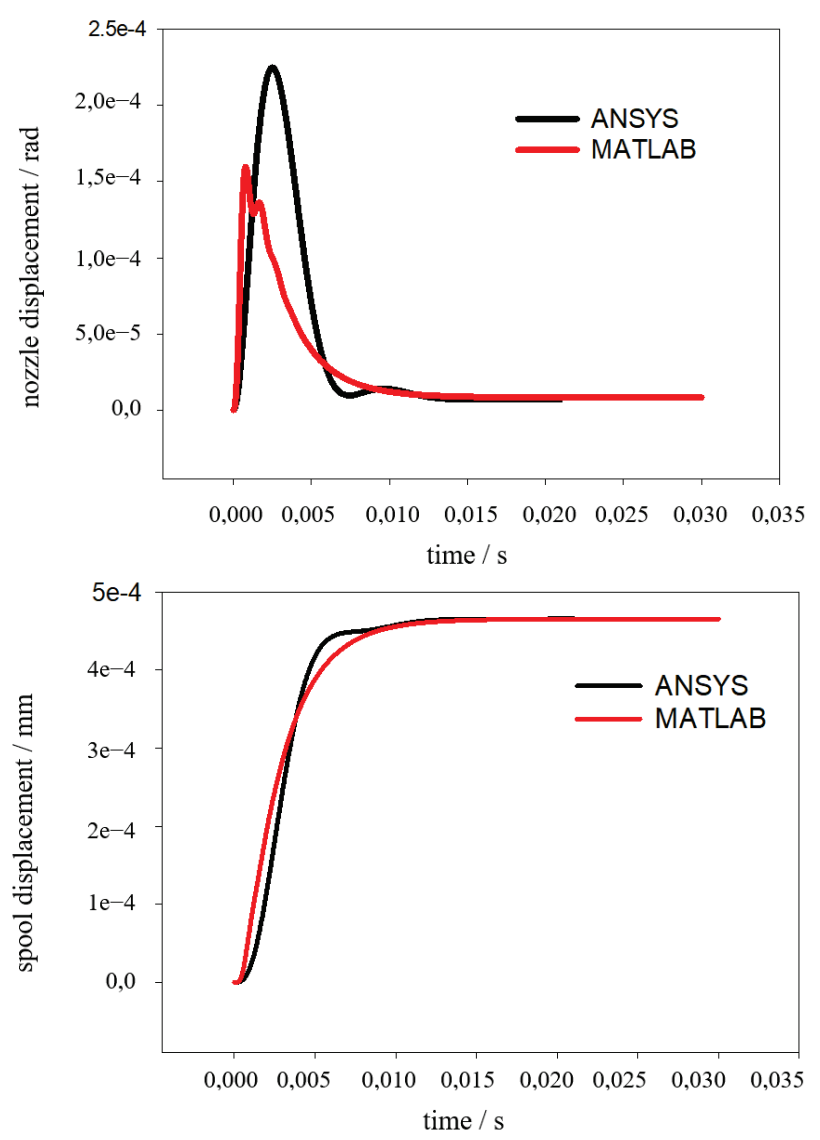

Figure 11 Displacement at the electromagnetic force of $0,15 \mathrm{~N} \cdot \mathrm{m}$ and the fluid force of $0,5 \mathrm{~N}$

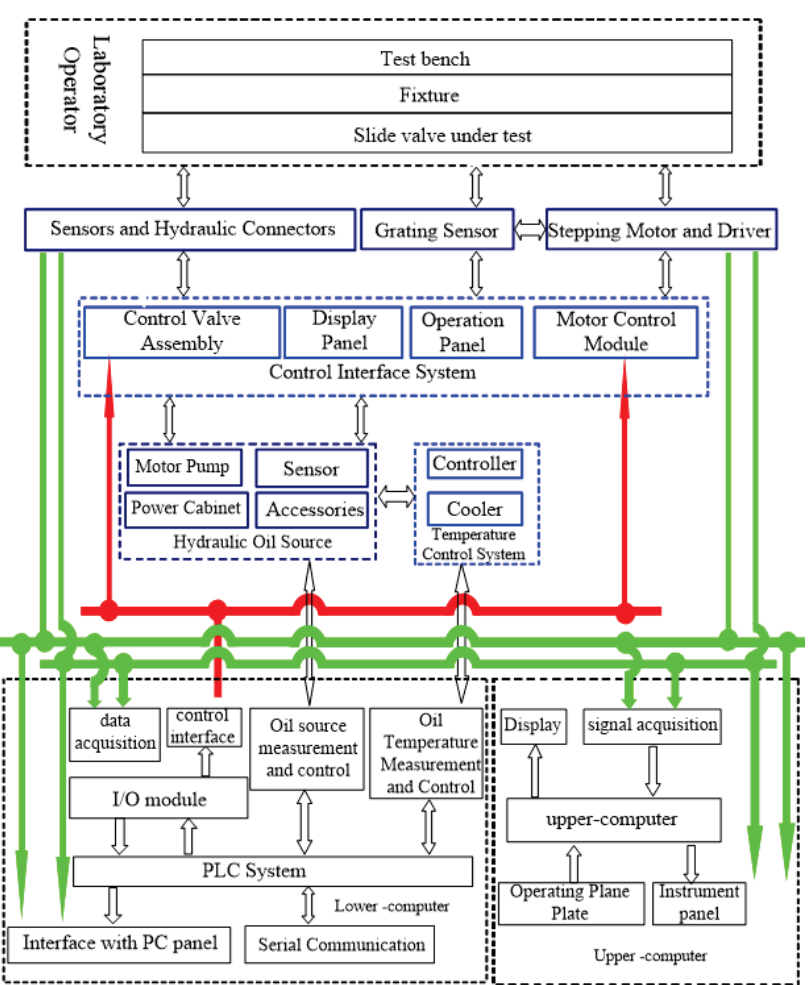

Figure 12 Valve flow test platform

The visual simulation was carried out according to the program in the APDL file, which contains the grid meshing, material properties, constraints, boundary conditions and solution methods. In light of the previous analysis, the armature is under the output torque of the torque motor, which is related to the deflection angle of the 
armature and the input current Eq. (2). According to Eq (4), the pressure difference across valve is already known. Moreover, the jet nozzle deflection angle is related to the spool velocity. For the armature-feedback rod assembly, the transient dynamics method was selected due to the constant changes to the load on the armature and the spool. Fig. 10 presents the spool and nozzle displacements simulated at the input current of $15 \mathrm{~mA}$.

It can be seen from Fig. 11 that the system was basically stable at $0,02 \mathrm{~s}$, the nozzle displacement peaked at $0,0024 \mathrm{~s}$ and then dropped back close to the zero position, and the spool became stable at $0,466 \mathrm{~mm}$.

\section{EXPERIMENTAL VERIFICATION}

\subsection{Design of Remote Wireless Debugging Software}

As shown in Fig. 12, a valve flow test platform was set up to test the oil flow between the sleeves.

The test platform mainly contains a hydraulic console, a hydraulic oil source system, an oil temperature control system, a spool installation and drive system and a computer measurement and control system. Among them, the hydraulic console offers various indicator lights, buttons and display instruments, plus a sliding valve drive system; the hydraulic oil source system provides the test platform with pressure and oil; the oil temperature control system keeps the oil temperature constant through the measurement; the spool installation and drive system mainly fixes the spool with a clamp and drives its movement with a high-precision stepping motor and a ball screw pair, providing an important guarantee of measuring accuracy; the computer measurement and control system collects signals through the test via the conditioning circuit, and processes and displays the acquired signals.

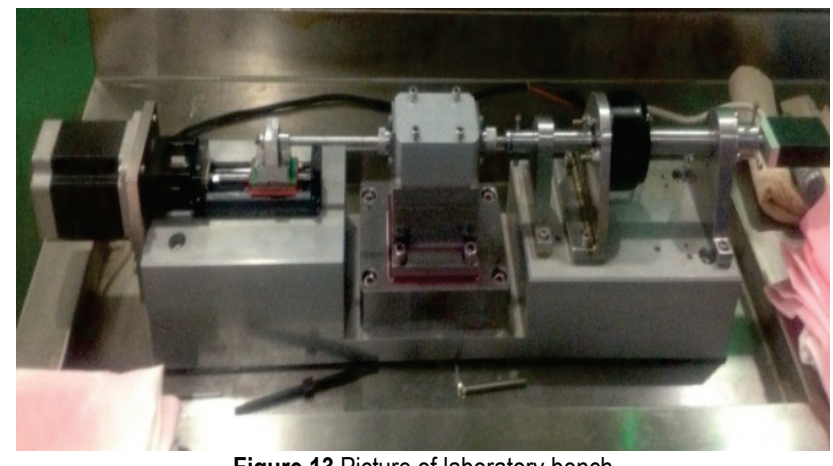

Figure 13 Picture of laboratory bench

During the test, Y-H 15 aviation hydraulic oil was supplied at $21 \mathrm{MPa} \pm 0,05 \mathrm{MPa}$ and controlled within 25 ${ }^{\circ} \mathrm{C} \pm 3{ }^{\circ} \mathrm{C}$. The pollutant level of the oil satisfies the requirement in the national standard GJB420A-1996.

The photo of test platform is shown in Fig. 13.

As shown in Fig. 14, the test results and the calculation results of the flow rate when the spool moves from the initial position to the right by $131 \mu \mathrm{m}$ are compared. Obviously, the test results were basically the same with the simulated results. When the valve opening is $0-100 \mu \mathrm{m}$, the error meets the requirements. The existence of small errors is inevitable because the test valve cannot act as an ideal zero-opening valve.

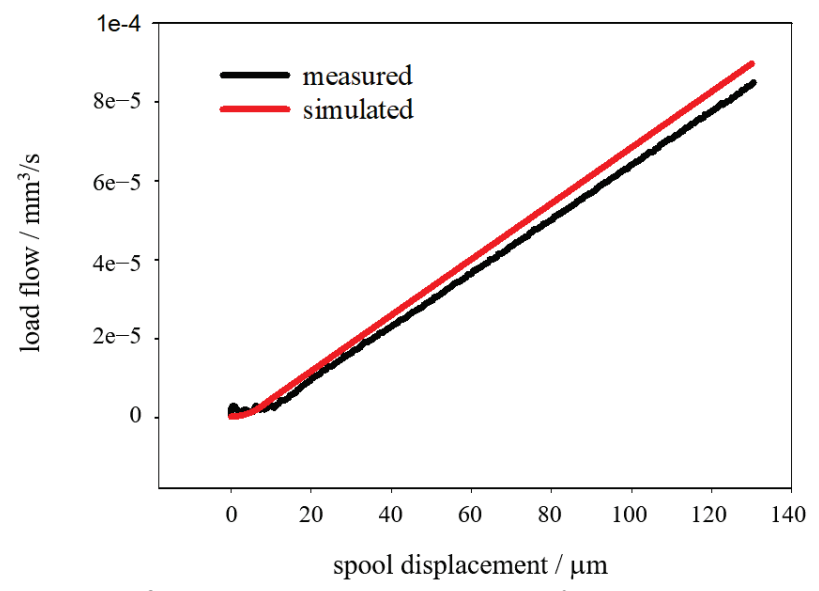

Figure 14 Comparison between the measured load flows with the simulated results

\section{CONCLUSIONS}

The working process of jet pipe servo valve is very complex, involving the interaction of three physical fields. The traditional lumped parameter model cannot accurately predict the performance of servo valve, which hinders the localization of jet pipe servo valve. In order to improve the prediction accuracy of the performance of jet pipe servo valve, based on the basic theory of magnetic field, flow field and structural field, this paper adopts the numerical calculation method based on unstructured grid to simulate the working process of servo valve dynamically. The numerical results are compared with the traditional lumped parameter method. Through some experimental verification methods, the numerical calculation method adopted in this paper is verified to have high accuracy.

The method used in this paper can be applied to the performance prediction of similar composite electrohydraulic equipment.

\section{Acknowledgements}

Supported by the National Natural Science Foundation of China (Grant No. 51805403).

\section{REFERENCES}

[1] Zhao, J., Zhang, B., \& Chen, T. (2019). Research on valve core's clamping stagnation of double flapper-nozzle servo valve. High Technology Letters, 25(1), 65-73. https://doi.org/10.3772/j.issn.1006-6748.2019.01.009

[2] Zuo, X., Ruan, J., \& Sun, J. (2017). Stability Analysis of 2D Electro-hydraulic Pressure Servo Valve Based on Squeeze Oil Film Theory. Zhongguo Jixie Gongcheng / China Mechanical Engineering, 28(5), 537-543. https://doi.org/10.3969/j.issn.1004-132X.2017.05.006

[3] He, C., Liu, Y., \& Yavuzkurt, S. (2018). Large-Eddy Simulation of Circular Jet Mixing: Lip- and Inner-ribbed Nozzles. Computers \& Fluids, 168, 245-264. https://doi.org/10.1016/j.compfluid. 2018.04.018

[4] Wu, L., Chen, K., \& Guo, Y. (2019). Research on cavitation phenomena in pilot stage of jet pipe servo-valve with a rectangular nozzle based on large-eddy simulations. AIP Advances, 9(2), 025109. https://doi.org/10.1063/1.5038402

[5] Wang, Y. \& Yin, Y. (2019). Performance reliability of jet pipe servo valve under random vibration environment. Mechatronics, 64, 102286.

https://doi.org/10.1016/j.mechatronics.2019.102286 
[6] Wu, L., Chen, K., \& Zhan, C. (2018). Snapshot POD analysis of transient flow in the pilot stage of a jet pipe servo valve. Journal of Turbulence, 19(10), 889-909. https://doi.org/10.1080/14685248.2018.1524579

[7] Zhang, K., Yao, J. Y., \& Jiang, T. M. (2014). Degradation assessment and life prediction of electro-hydraulic servo valve under erosion wear. Engineering Failure Analysis, 36, 284-300. https://doi.org/10.1016/i.engfailanal.2013.10.017

[8] Hu, J., Yang, Z., Huang, Z., Jin, Y., Yu, B., \& Kong, X. (2018). Flow measurement for the pre-stage of jet pipe servo valve using 2D -PIV technique. International Journal of Fluid Power, 19(3), 165-172. https://doi.org/10.1080/14399776.2018.1514931

[9] Filo, G., Lisowski, E., \& Rajda, J. (2019). Flow analysis of a switching valve with innovative poppet head geometry by means of CFD method. Flow Measurement and Instrumentation, 70, 101643. https://doi.org/10.1016/j.flowmeasinst.2019.101643

[10] Li, Y. (2016). Mathematical modelling and characteristics of the pilot valve applied to a jet-pipe/deflector-jet servovalve. Sensors \& Actuators A Physical, 245, 150-159. https://doi.org/10.1016/j.sna.2016.04.048

[11] Wu, L., Chen, K., \& Zhan, C. (2018). Snapshot POD analysis of transient flow in the pilot stage of a jet pipe servo valve. Journal of Turbulence, 19(10), 889-909. https://doi.org/10.1080/14685248.2018.1524579

[12] Kang, S., Yan, H., Li, C., Wang, F., \& Wang, S. (2017). Modeling of the flow distribution and characteristics analysis of the pilot stage in a deflector jet servo valve. Journal of Harbin Engineering University, 38(8), 1293-1302. https://doi.org/10.11990/jheu.201605009

[13] Chen, J., Yuan, Z., Guo, Q., Chu, Y. (2017). Dynamic flow field analysis of the prestage of jet pipe servo valve. Chinese Journal of Scientific Instrument, 38(7), 1731-1737.

[14] Ding, Y., Jin, Y., Zhang, X., Wei, T., \& Xie, Z. (2016). The design of the integrated jet-pipe servo-valve with high reliability. IEEE International Conference on Aircraft Utility Systems, 16484921. https://doi.org/ 10.1109/AUS.2016.7748197

[15] Zhang, Q., Yan, L., \& Duan, Z. (2020). High Torque Density Torque Motor with Hybrid Magnetization Pole Arrays for Jet Pipe Servo Valve. IEEE Transactions on Industrial Electronics, 67(3), 2133-2142. https://doi.org/10.1109/TIE.2019.2903761.

[16] Xu, M., Zeng, S., \& Guo, J. (2014). Reliability modeling of a jet pipe electrohydraulic servo valve. 2014 Reliability and Maintainability Symposium, 1-6. https://doi.org/10.1109/RAMS.2014.6798480

[17] Pham, X. H. S., Yin, Y., \& Zhang, X. (2012). Optimal Design for Torque Motor of Jet Pipe Electro-hydraulic Servo-valve Based on Dynamic Stiffness. International Conference on Intelligent Human-machine Systems \& Cybernetics, 2, 183-186. https://doi.org/10.1109/IHMSC.2012.140

[18] Carla, B. \& Giuseppe, P. (2017). Numerical multiphysics modelling for the assessment of thermo-physical and energy performance of an advanced semi-opaque active façade, International Journal of Heat and Technology, 35(1), 639644. https://doi.org/ 10.18280/ijht.350322

[19] Tian, F., Cao, W. D., Dai, X. L., \& Ou, M. X. (2018). Flow characteristics of the new type of mixer in wastewater treatment. International Journal of Heat and Technology, 36(3), 913-918. https://doi.org/10.18280/ijht.360318

[20] Garg, R., Thakur, H., \& Tripathi, B. (2018). Numerical simulation of two-dimensional fluid flow problem using truly mesh free method. Mathematical Modelling of Engineering Problems, 5(4), 357-364. https://doi.org/10.18280/mmep.050412
[21] Gomboc, T. \& Zadravec, M. (2018). Numerical model of three stage spray drying for zeolite 4A-water suspensions coupled with a CFD flow field. International Journal of Simulation Modelling, 17(3), 217-228. https://doi.org/10.2507/IJSIMM18(2)462

\section{Contact information:}

Ying Zhang, Doctor,

(Corresponding author)

School of Optoeletronic Engineering, Xi'an Technological University, Xi'an 710021, China

E-mail: zhangying_1102@163.com

Junshuo Chen, Doctor

School of Electronic Control, Chang'an University,

Xi'an, 710064, China

E-mail: jsch@chd.edu.cn 